IOSR Journal of Pharmacy

e-ISSN: 2250-3013, p-ISSN: 2319-4219, www.iosrphr.org

Volume 2 Issue 6 || || Nov-Dec. 2012 || || PP.10-20

\title{
High quality at low cost—how can a clinical pathway contribute towards reconciling this apparent contradiction?
}

\author{
Dr. Tobias Romeyke ${ }^{1}$, Professor Dr. Harald Stummer ${ }^{2}$ \\ ${ }^{1,2}$ Department for Public Health and Health Technology Assessment \\ University for Health Sciences, Medical Informatics and Technology \\ Opernring 5/2, 1010 Vienna, Austria
}

\begin{abstract}
The cost-intensive care of a growing number of pain patients means that hospitals specialising in interdisciplinary pain therapies as part of providing acute inpatient care are placed under increasing pressure in ensuring that the quality of care remains high while the costs incurred remain low. The purpose of the present study is to investigate whether a clinical pathway for multimode pain therapy in diseases and disturbances of the musculoskeletal system and connective tissue remains the quality of care high while the costs incurred remain low.

Analysis is necessary of the core processes of pain therapy in respect of quality and costs, taking account of the ages and comorbidities of the two groups of subjects. This analysis examines the pain intensity, the costs incurred for the care personnel, therapy minutes involved, and hospitalisation duration.

It 's shown that costs can be lowered as a result of the CP and that, despite a reduction in the duration of hospitalisation, the pain intensity on being discharged from hospital is no lower than for the comparison group without $C P$.

A clinical pathway, referred to indications, should be developed by all personnel involved in the therapy process and, in the medium term, should become a fixed component of operative and strategic business management.
\end{abstract}

Keywords-clinical pathway, DRG, pain therapy, personnel costs of the nursing service, quality, pain intensity, duration of hospitalisation, secondary diagnoses, therapy minutes.

\section{INTRODUCTION}

Pain numbers among those symptoms that can severely and persistently impair quality of life. Correspondingly great are today's expectations placed on researchers and doctors to provide drug and therapeutic treatment strategies for the elimination, or at least alleviation, of chronic pain conditions.

In Europe there are millions of people who suffer from long-term pain that required treatment [1]. These patients are generally resistant to unimodal outpatient therapy and must be treated in specialized hospitals with multimode approaches. An interdisciplinary treatment of chronic pain is effectively $[2,3]$ and can also reduce opioid use and increasing return to work [4].

Fig. 1 illustrates the system used for the different pain therapies in the G-DRG system (German diagnosis related groups). According to this, the performance of multimode pain therapy (OPS 8-918) combined with the major diagnosis category (MDC) yields four different pain DRGs: I42Z, U42Z, Z44Z and B47Z.

The MDC defines the section classification of the German DRG catalogue. The major diagnostic groups organize the DRGs according to the organ system or to the cause of the disease. 
Fig. 1: Pain therapies in the G-DRG System

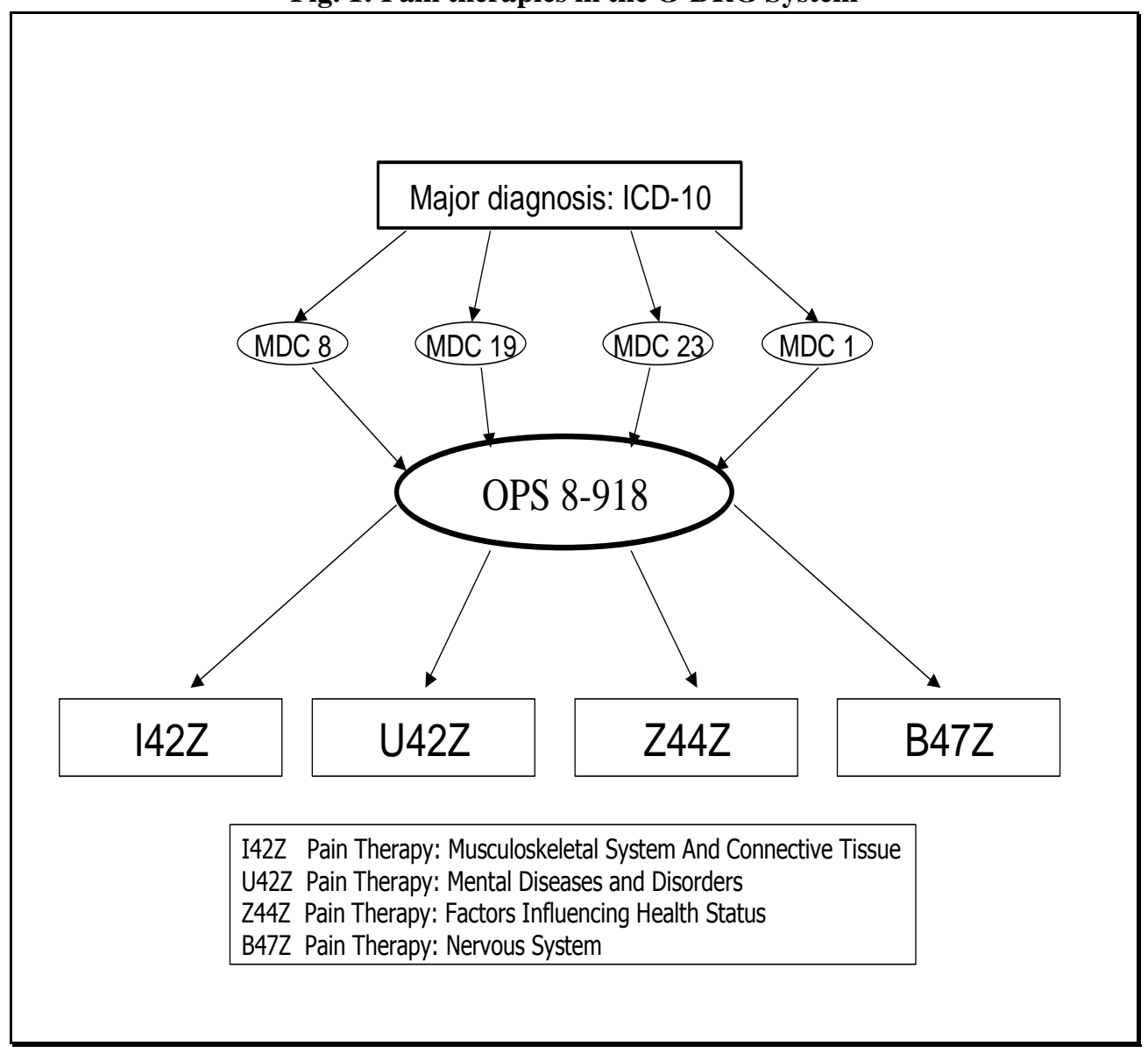

Chronic pain cause high health care costs [5].

Many specializations are necessary in order to provide a multimode pain therapy, in Germany the procedure 8918 (OPS 2010).

The complexity of providing the services needed is reflected in the costs of the pain therapy. These are also influenced by the continually growing personnel and operating costs in the hospital sector (DKG 2009). Hospital management is faced with the challenge of lowering the costs of providing services, while simultaneously improving the quality of care. In order to achieve this aim, a clinical pathway is developed which is intended to make a contribution to improving core process control in the multidisciplinary team.

In the present study, the area of application of the clinical pathway encompasses pain therapy of diseases and disturbances of the musculoskeletal system and connective tissue.

A total of 65 patients are examined, of whom 55 are female. The ages of the study group range from 30 years to 87 years; the mean age of the patients without clinical pathway is 59.27 years and of those with clinical pathway 66.55 years. The duration of hospitalisation ranges from a minimum of 14 days to a maximum of 24 days.

\section{BACKGROUND}

Particularly in the surgical sector, treatment pathways are being developed in hospital and the associated costs and durations of hospitalisation are being analysed $[6,7,8,9]$. This can be attributed to a high level of standardization and the continual repetition of processes in the surgical sector.

In contrast, interdisciplinary pain therapy combines many professional groups in the process of providing services (Fig. 2), which makes standardization appear very difficult. Based on a definition from the requirements of Procedure 8-918, it is possible to derive pathway components and to develop a standardized approach. 
High quality at low cost—how can a clinical pathway contribute towards...

Fig. 2: Diagnostic and therapeutic components of multimode pain therapy OPS 8-918

\title{
Mnltimodal pain therapy OPS 8-918
}

\author{
Psychological specialisation
}

\section{Respomible therapy management with add. itional qualification "special pain therap"}

\section{Inter disciplinary diagnosis by at le ast two different areas of specialisation (psychiatric, psychosomatic or psychological)}

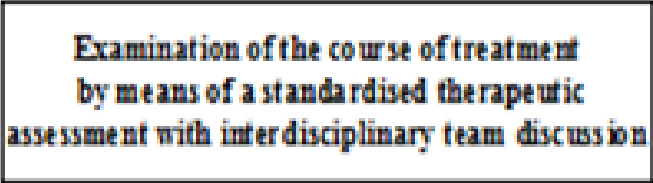

Examination of the course of treatment ssment with inter disciplinary team discussion
Treatment with involvement of a psychiatric or psycho soma tic area of specialisation

\section{Interdisciplinary treatment and diagnosis}

Thus, starting from a structured pain anamnesis and interdisciplinary diagnosis, a clinical pathway is intended to lead former therapy-resistant outpatients with multiple chronic pain conditions to a fixed therapeutic target within a predefined duration of hospitalisation. By means of an interdisciplinary therapy team and a holistic approach, the aim is to achieve a reduction in pain intensity and effective and efficient treatment of the secondary diagnoses associated with the main diagnosis. In providing the service, a high-quality outcome and cost efficiency must not be mutually exclusive. Analysis is necessary of the core processes of multimode pain therapy in respect of quality indicators and costs, taking account of the ages and co morbidities of the two groups of subjects. This analysis examines the pain intensity at the beginning and end of the period of hospitalisation, the costs incurred for the care personnel, the minutes of therapy involved, and the duration of hospitalisation.

A vertically aligned visual analogue scale (VAS) is used to determine the pain intensity [10]. Ferraz et al. were able to confirm in their study the reliability of estimating pain intensity by means of the VAS [11]. The VAS range is marked only by the endpoints, which are generally a distance of $10 \mathrm{~cm}(100 \mathrm{~mm})$ apart. The patient indicates the severity of their current pain by drawing a line between 0 and 100. In the present study, the pain intensity is recorded when the patient is admitted, and on the last treatment day, enabling the development of the subjective pain intensity to be evaluated at the beginning and end of the pathway.

The diagnosis, therapy and nursing is preceded by an admission management process that already takes place before the patient makes demands on the infrastructure of the hospital. The clinical pathway should already be defined at this point. This requires a central patient admission management system that promises improvement in how the process is organized, optimisation of communication and, therefore, stronger orientation on the client [12]. In addition to abolishing interfaces, the admission process can be speeded upwhich not only benefits the patient, but also increases the satisfaction of the office-based doctor.

In addition to the generation of pain anamnesis data on the day of admission, a continual co morbidity analysis takes place that defines the further direction of the diagnostic measures. All the professional groups involved in the therapy process make their contribution to achieving the therapeutic target. The standardized documentation simultaneously meets the criteria required by the German appropriateness protocol (G-AEP) and its preamble as 
the basis for evaluating the necessity of hospitalisation. This catalogue of criteria, which was already developed by Gertman and Restuccia during the 1980s and continually adapted [13], uses medical test parameters to evaluate an appropriate use of the inpatient resources.

The diagnostic and therapeutic methods defined in the catalogue of procedures (Fig. 2: Diagnostic and therapeutic components of multimode pain therapy) should be an integral component of the hospital organization in order to conform to the statutory regulatory concept of achieving a successful therapeutic outcome and ensuring remuneration of the case.

Moreover, high-quality care must guarantee that the clinical pathway used includes not only evidence based therapeutic procedures, but also those that have proved their worth in inpatient practice [14]. An essential part of the therapy of patients with chronic pain conditions is medically prescribed drug treatment in accordance with the WHO graded system. As part of the regulative therapy, autogenic training/pain control training is a fixed component of the clinical pathway. The therapeutic targets are relaxation of the body's musculature in order to alleviate pain, the reduction of anxiety and, by means of regular recovery phases, an improvement in general physical and mental performance. Studies have shown positive effects on mood, cognitive performance and quality of life [15]. Another key aspect of the regulative therapy is promotion of the patient's own resources in learning how to cope with pain [16] while taking the rhythms of life into account.

Kinesitherapeutic interventions with low kinetic energy are an evidence based component [17] of the pain therapy clinical pathway.

Nursing professionals play an especially important role in the multidisciplinary team. In addition to the traditional nursing measures, all nurses have special expertise in complementary therapeutic methods - in other words, in active methods that are used in addition to mainstream medicine. These methods include, for example, applications from hydro- and thermo therapy, phytotherapy, special pain therapy and derived processes. Therapeutic methods from the therapy area "other physical measures", such as massage, are used as a fixed component of the clinical pathway by physiotherapists, staff employed in physical therapy, and balneotherapists. Specific massage techniques can exert a positive effect on pain reduction. Brattberg (1999) studied the efficacy of connective tissue massage in patients with soft tissue rheumatism and established a significant alleviation of pain compared with the control group [18]. However, he stated that further studies were needed in order to confirm the mode of action with certainty. In addition to connective tissue massage and classical massage, acupuncture massage is also part of the therapeutic pathway.

Classical acupuncture is one of the approaches that significantly reduces pain in rheumatic diseases $[19,20]$, but thermo therapy [21,22] is also a permanent component of the clinical pathway for DRG I42Z (multimode pain therapy in diseases and disturbances of the musculoskeletal system and connective tissue).

After completed diagnosis, therapy and nursing measures, discharge management at the end of the period of hospitalisation must be planned on the basis of the daily documentation of diagnoses requiring the use of resources, and the therapeutic progression.

Preparing for the patient's exit from the clinical pathway within discharge management once again involves all the participants in the therapy process. Within the final interdisciplinary assessment, the extent is examined to which the therapy targets defined by the professional groups have been achieved. Targets which were not achieved are defined as variances and documented. These deviations are the basis for targeted therapeutic prescriptions as part of ongoing pain therapy on an outpatient basis. In this connection, the measures performed and the therapeutic progression are also important for the doctor who will provide further treatment. The guidelines in the clinical pathway enable the relevant information to be passed on to the office-based doctor at the time the patient is discharged. Evaluation of the variances can also contribute towards reducing deviations in the medium term and to improving the quality of the care process. In addition, the analysis of variance serves as a powerful clinical audit tool for reviewing all aspects of patient care [23]. In order to completely finalize the core process, the hospital doctor integrates and monitors his diagnosis grouping for the last time. The grouping software records the patient data and calculates the revenues for the interdisciplinary treatment provided. This document is examined by Controlling, together with the patient's file and the pathway documentation.

The active role of the medical service, and especially of the medical management, is of considerable importance for achieving optimal therapeutic outcomes in the sense of networking between evidence and internal hospital expertise [24].

\section{METHODS}

The implementation of a clinical pathway can result in a lowering of inpatient costs and a reduction of the duration of hospitalisation [25].

In order to examine the influence of the clinical pathway on the costs of the DRG 142Z, it is necessary to perform a survey of patient related case costs.

The Calculation Manual issued by the Institut für das Entgeltsystem im Krankenhaus (InEK) (Institute for the Hospital Remuneration System) is used in this study because it is also used by more than 200 hospitals as 
a proven instrument for further development of the German diagnosis related group system (G-DRG). This is being continually developed and improved by the institute.

Firstly, the lists of totals and balances from the accounting system, which must agree with the expenditures in the profit and loss account of the audited annual financial statements, are drawn up for the DRG case calculation. Non-DRG relevant expenditures, for example those relating to other periods, and extraordinary expenditures (e.g. closure and restructuring of parts of the business), are not taken into account.

Because of the complexity of the material, only excerpts from individual steps in the procedure are dealt with in the following. Personnel costs are especially significant, since they take up the largest share of costs in the fixed case-price. In recording the personnel costs, personnel expenditures are differentiated according to accounting groups, and types of service are separated. In allocating the personnel costs, the personnel cost types of the medical service, the nursing service, the medical technical service and the off-ward service must be included; the scope of these is measured by means of the time records of the personnel. Plausibility and conformity checks are performed by the $\operatorname{InEK}$, thereby ensuring a correct distribution of costs.

As further preparation for cost centre accounting, the relevant scope of service for fixed case-prices must be determined for each cost centre by assigning the cost centres to categories according to how they relate to their cost objectives. In doing this, a distinction is made between direct cost centres that provide medical care services directly to the patient and indirect cost centres (InEK 2007). Hospital services that do not impinge directly on the patient are divided into "medical infrastructure" and "non-medical infrastructure". Mixed cost centres are those that provide both DRG relevant services and non-DRG relevant services and must therefore be differentiated from cost centres that must be excluded because they include only non-DRG relevant services. The cost centre accounting prepares for job order cost accounting in that it distributes the costs of indirect cost centres between the direct cost centres and the cost centres to be excluded. The cost types of the direct cost centres are collected into cost-type groups. The distribution of the indirect cost centres between the direct cost centres and the cost centres to be excluded, based on source-related allocation keys, is done by the procedure of in-house service accounting (InEK 2007).

In the final stage of the cost accounting, within the job order cost accounting, the general DRG relevant costs booked to the direct cost centres are allocated source-related to the cases receiving service. The cost rates for the cost-type groups are calculated after generation of the costs and services data.

The personal costs of staff, material costs for drugs and other medical requirements are also calculated. The final result comprises the total costs of the DRG I42Z with and without clinical pathway. Comparison of the costs of the individual cost-type groups with and without clinical pathway allow for further interpretations of the results obtained.

Both the statistical and the graphical presentations were generated using SPSS for Windows $\odot$, Version 15.0. Error beams were used to illustrate the means for normally distributed samples; because of the points are scattered over a large area, the standard errors were used as the spread. Box and whiskers plots were used to visualize the medians and quartile separations for samples with non-normal distribution. In such cases, the median provides an overview of the symmetry of the distribution. A symmetrical distribution is a prerequisite for an outcome-oriented interpretation of statistical parameters and for the performance of many statistical tests. The study design was a non-randomised controlled trial.

\section{RESULTS}

Analysis of secondary diagnoses for each patient

The mean number of secondary diagnoses among all 65 subjects was 6.17, with a minimum of 2 and a maximum of 12 secondary diagnoses (Table 1).

For a comorbidity analysis, the secondary diagnoses for each patient were divided into diagnosis groups labelled with a DC (diagnostic category) based on the classification system of the major diagnostic category of the German DRG catalogue (Table 2).

Table 1: Number of secondary diagnoses

\begin{tabular}{|l|l|l|}
\hline $\mathrm{N}$ & & 65 \\
\hline & & \\
\hline Mean & 6.17 \\
\hline Standard error of the mean & .282 \\
\hline Median & 6.00 \\
\hline Standard deviation & 2.275 \\
\hline Minimum & 2 \\
\hline Maximum & 12 \\
\hline \multirow{3}{*}{ Percentile } & 25 & 5.00 \\
\cline { 2 - 3 } & 50 & 6.00 \\
\cline { 2 - 3 } & 75 & 8.00 \\
\hline
\end{tabular}


High quality at low cost—how can a clinical pathway contribute towards...

Table 2: Major Diagnostic Category (MDC) of German Diagnosis Related Groups

\begin{tabular}{|l|l|}
\hline MDC & Description \\
\hline 0 & Pre-MDC \\
\hline 1 & Nervous System \\
\hline 2 & Eye \\
\hline 3 & Ear, Nose, Mouth And Throat \\
\hline 4 & Respiratory System \\
\hline 5 & Circulatory System \\
\hline 6 & Digestive System \\
\hline 7 & Hepatobiliary System And Pancreas \\
\hline 8 & Musculoskeletal System And Connective Tissue \\
\hline 9 & Skin, Subcutaneous Tissue And Breast \\
\hline 10 & Endocrine, Nutritional And Metabolic System \\
\hline 11 & Kidney And Urinary Tract \\
\hline 12 & Male Reproductive System \\
\hline 13 & Female Reproductive System \\
\hline 14 & Pregnancy, Childbirth And Puerperium \\
\hline 15 & Newborn And Other Neonates (Perinatal Period) \\
\hline 16 & $\begin{array}{l}\text { Blood and Blood Forming Organs and Immunological } \\
\text { Disorders }\end{array}$ \\
\hline 17 & $\begin{array}{l}\text { Myeloproliferative DDs } \text { Poorly Differentiated } \\
\text { Neoplasms) }\end{array}$ \\
\hline $18 \mathrm{~A}$ & Human Immunodeficiency Virus Infection \\
\hline $18 \mathrm{~B}$ & Infectious and Parasitic DDs \\
\hline 19 & Mental Diseases and Disorders \\
\hline 20 & Alcohol/Drug Use or Induced Mental Disorders \\
\hline $21 \mathrm{~A}$ & Multiple Significant Trauma \\
\hline $21 \mathrm{~B}$ & Injuries, Poison And Toxic Effect of Drugs \\
\hline 22 & Burns \\
\hline 23 & Factors Influencing Health Status \\
\hline & \\
\hline
\end{tabular}

The secondary diagnostic groups surveyed for all 65 patients were: musculoskeletal system and connective tissue (DC 08), endocrine, nutritional and metabolic system (DC 10), circulatory system (DC 05), mental diseases and disorders (DC 19), nervous system (DC 1) and factors influencing health status (DC 23).

It was found that of the $\mathrm{n}=36$ patients without clinical pathway, 22 patients had secondary diseases from DC 8,17 patients diseases from DC 5, 16 patients secondary diagnoses from DC 10, 24 patients diseases from DC 19, and 11 patients diseases from DC 23.

Of the 29 patients with clinical pathway, 23 patients have secondary diseases from DC 8, 15 patients have diseases from DC 5, 16 patients have secondary diagnoses from DC 10, 17 patients have diseases from DC19, and 7 patients from DC 23 (Fig. 3).

Fig. 3: Secondary diagnostic groups

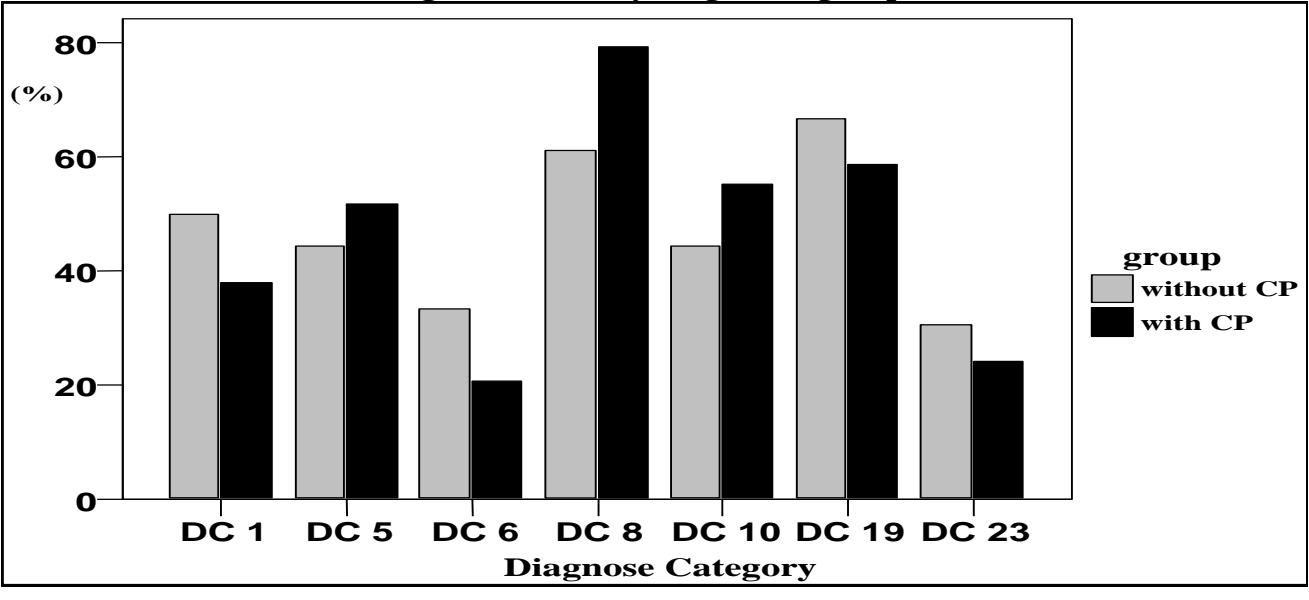


Age

The ages of the subjects range from 30 to 87 years. $25 \%$ of the patients were younger than 48 years, $50 \%$ younger than 56 years and $25 \%$ of the patients were older than 63 years. The standard deviation was 11.272 years (Fig. 4).

Fig. 4: Distribution of the ages of the patients

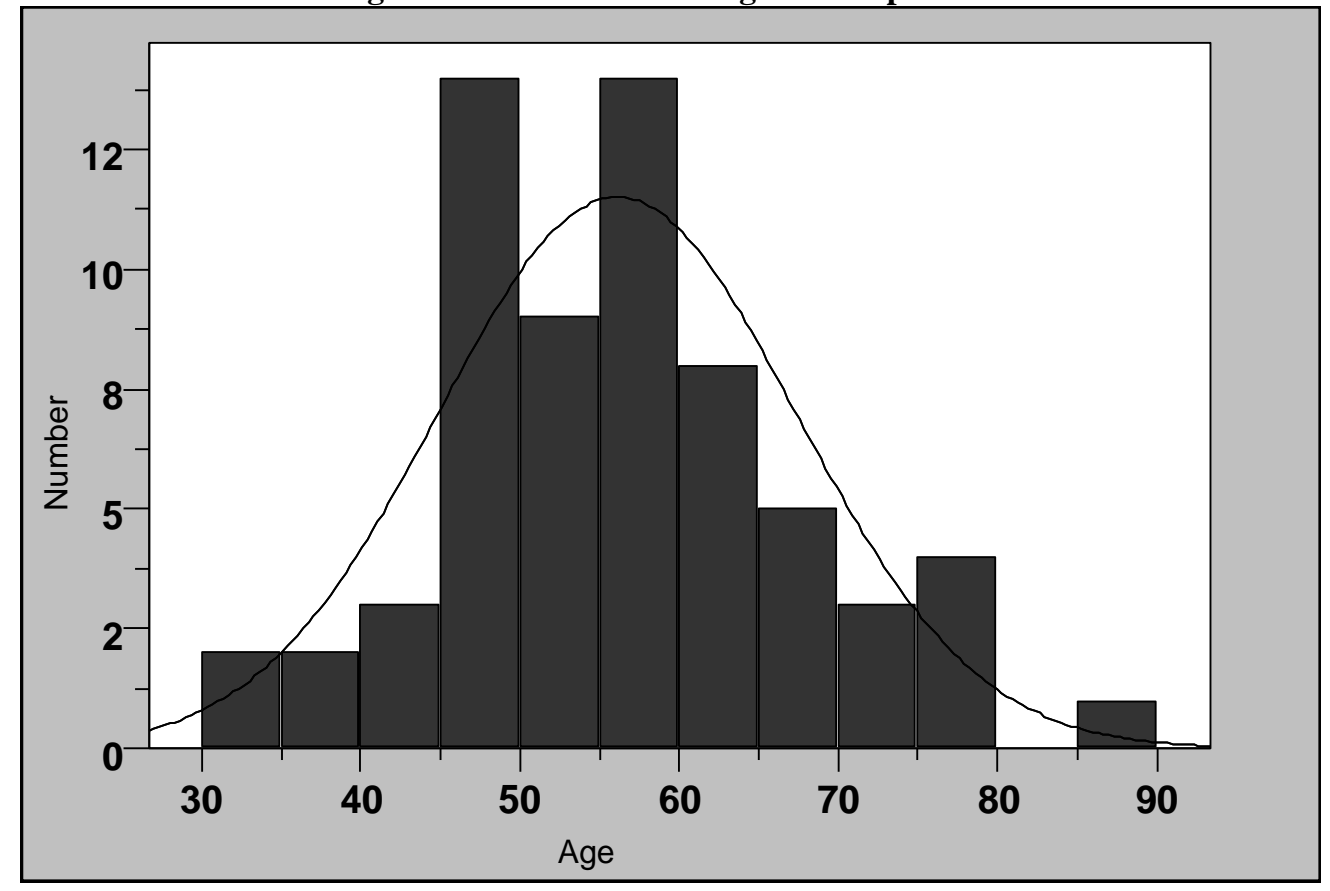

\section{Pain intensity}

As a quality indicator for the inpatient therapy, the pain intensity was recorded for all 65 patients on admission and on discharge, using the visual analogue scale (VAS).

The mean pain intensity (pi) of the patients on admission was 82 from a maximum of 100 points; the mean intensity on discharge was 45 from 100. The minimum on admission was 60 and on discharge was 0 from 100 points on the VAS. The maximum pain intensity on admission was 100 and on discharge 90 from 100 points (Table 3a, b; Fig. 5: Pain intensity on admission and discharge). Results: without CP / with CP on admission (Standard deviation 11.777 / 11.461; Standard error of the mean 1.963 / 2.128; Median 85.00 / 80.00). Without CP / with CP on discharge (Standard deviation 22.259 / 16.096; Standard error of the mean 3.710 / 2.989; Median 47.50 / 40.00).

Table 3a: Pain intensity on admission

\begin{tabular}{|l|l|l|l|l|l|}
\hline Group & Mean & $\begin{array}{l}\text { Standard } \\
\text { deviation }\end{array}$ & $\begin{array}{l}\text { Standard } \\
\text { error of the } \\
\text { mean }\end{array}$ & Median & N \\
\hline without CP & $\mathbf{8 3 , 0 8}$ & 11,777 & 1,963 & $\mathbf{8 5 , 0 0}$ & 36 \\
\hline with CP & $\mathbf{8 0 , 6 9}$ & 11,461 & 2,128 & $\mathbf{8 0 , 0 0}$ & 29 \\
\hline Total & $\mathbf{8 2 , 0 2}$ & 11,609 & 1,440 & $\mathbf{8 0 , 0 0}$ & $\mathbf{6 5}$ \\
\hline
\end{tabular}

Table 3b: Pain intensity on discharge

\begin{tabular}{|l|l|l|l|l|l|}
\hline Group & Mean & $\begin{array}{l}\text { Standard } \\
\text { deviation }\end{array}$ & $\begin{array}{l}\text { Standard } \\
\text { error of the } \\
\text { mean }\end{array}$ & Median & N \\
\hline without CP & 46,92 & 22,259 & 3,710 & 47,50 & 36 \\
\hline with CP & 42,69 & 16,096 & 2,989 & 40,00 & 29 \\
\hline Total & 45,03 & 19,718 & 2,446 & 40,00 & 65 \\
\hline
\end{tabular}


Fig 5: Pain intensity on admission and discharge

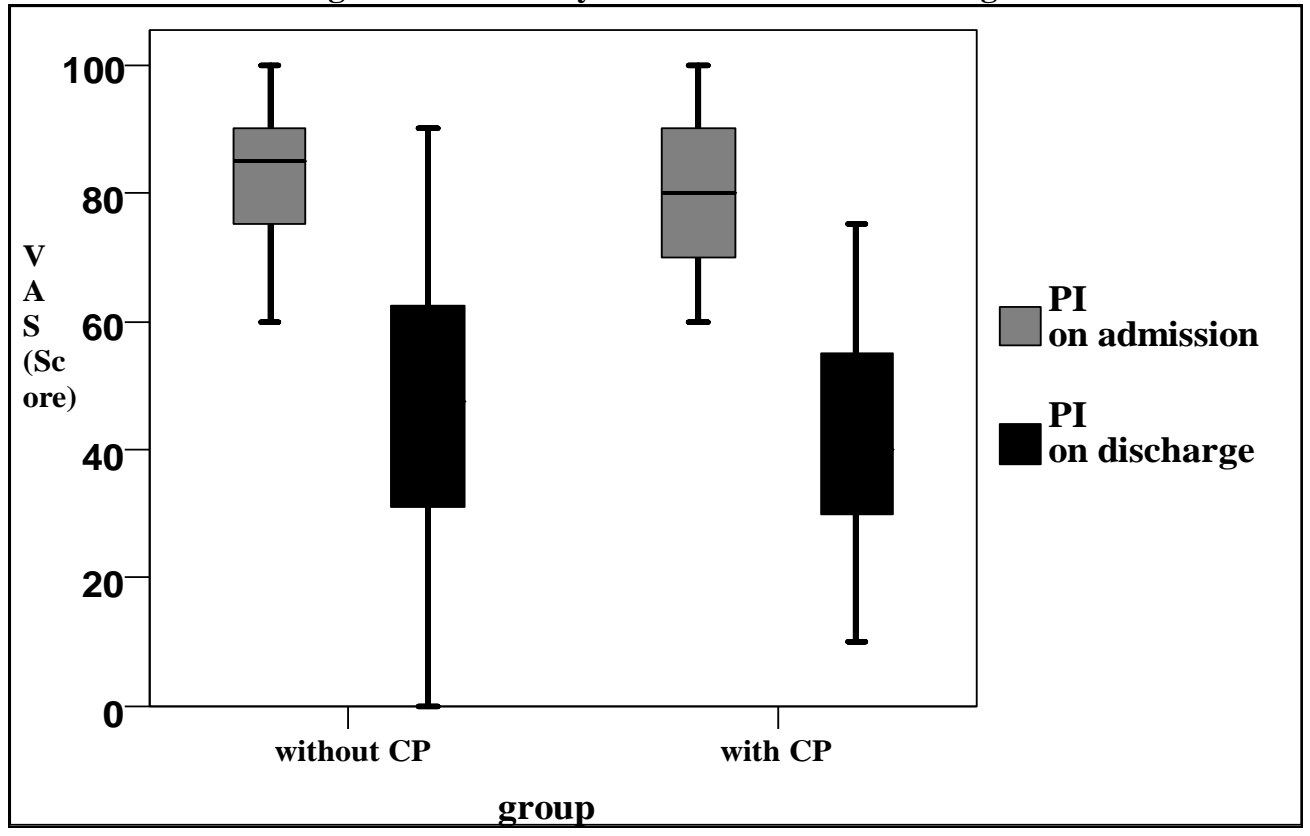

Comparison of the two groups (with $\mathrm{CP}$ and without $\mathrm{CP}$ ) with regard to the parameters surveyed

The parameters studied - secondary diagnoses and pain intensity-did not conform to normal distribution (Kolmogorov-Smirnov $\mathrm{p}<0.000 ; \mathrm{p}=0.015$ ). After performing the Mann-Whitney $\mathrm{U}$ test, differences were not significant for secondary diagnoses (Mann-Whitney $U$ test; $p=0.214$ ) and for the parameter pain intensity (with and without $\mathrm{CP}$ on admission, Mann-Whitney $\mathrm{U}$ test: $\mathrm{p}=0.436$; with and without $\mathrm{CP}$ on discharge, Mann-Whitney U tests: $\mathrm{p}=0.386$ ).

Total costs of the nursing service for patients without CP vs. patients with CP

The personnel costs for the nursing service (Pcfns) comprise salary payments, statutory social contributions, pension contributions and other personnel expenses for the nursing service. The study shows that a reduction in these costs of $23 \%$ on average for clinical pathway patients (mean nursing personnel costs with CP of EUR 625.21 vs. mean nursing personnel costs of EUR 818.50 per patient without CP) is not accompanied by any reduction in the quality of the outcome (Fig. 6 and Table 4: Total costs of nursing for patients with CP vs. patients without $\mathrm{CP}$ ).

Fig. 6: Total costs of nursing for patients with $\mathrm{CP}$ vs. patients without $\mathrm{CP}$

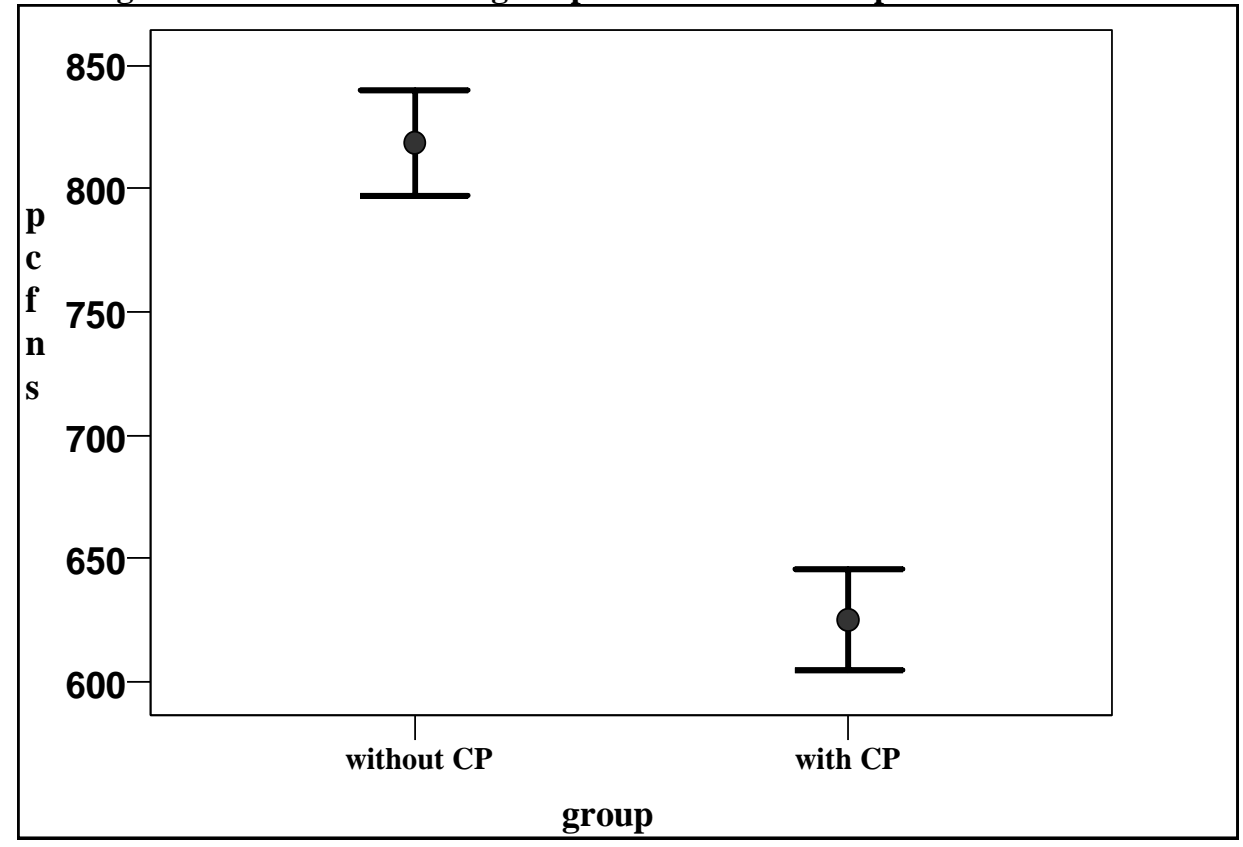


High quality at low cost—how can a clinical pathway contribute towards...

Table 4: Total costs of nursing for patients with CP vs. patients without CP

\begin{tabular}{|l|l|l|l|l|l|}
\hline Group & Mean & $\begin{array}{l}\text { Standard } \\
\text { deviation }\end{array}$ & $\begin{array}{l}\text { Standard } \\
\text { error of the } \\
\text { mean }\end{array}$ & Median & $\mathbf{N}$ \\
\hline without CP & $\mathbf{8 1 8 . 5 0}$ & $\mathbf{1 2 9 . 0 9 6}$ & $\mathbf{2 1 . 5 1 6}$ & $\mathbf{8 0 7 . 5 0}$ & $\mathbf{3 6}$ \\
\hline with CP & $\mathbf{6 2 5 . 2 1}$ & $\mathbf{1 0 9 . 8 4 1}$ & $\mathbf{2 0 . 3 9 7}$ & $\mathbf{6 3 1 . 0 0}$ & $\mathbf{2 9}$ \\
\hline
\end{tabular}

(Results without CP/with CP: Standard deviation 129.096/109.841; Standard error of the mean 21.516/20.397; Median 807.50/631.00).

The parameter total costs of nursing service showed normal distribution (Kolmogorov-Smirnov $\mathrm{p}=0.200$ ).

A statistical significance could be calculated for this difference: patients with $\mathrm{CP}$ vs. patients without $\mathrm{CP}=\mathrm{EUR}$ $625 \pm 110$ vs. EUR $819 \pm 129$; t-test: $\mathrm{p}=0.001$.

\section{Number of therapy minutes for patients with CP vs. patients without CP}

A mean of 2530 therapy minutes (tm) was used for patients with $\mathrm{CP}$; patients without $\mathrm{CP}$ received a mean of 3154 therapy minutes (Fig. 7).

Fig. 7: Number of therapy minutes for patients with $\mathrm{CP}$ vs. patients without $\mathrm{CP}$

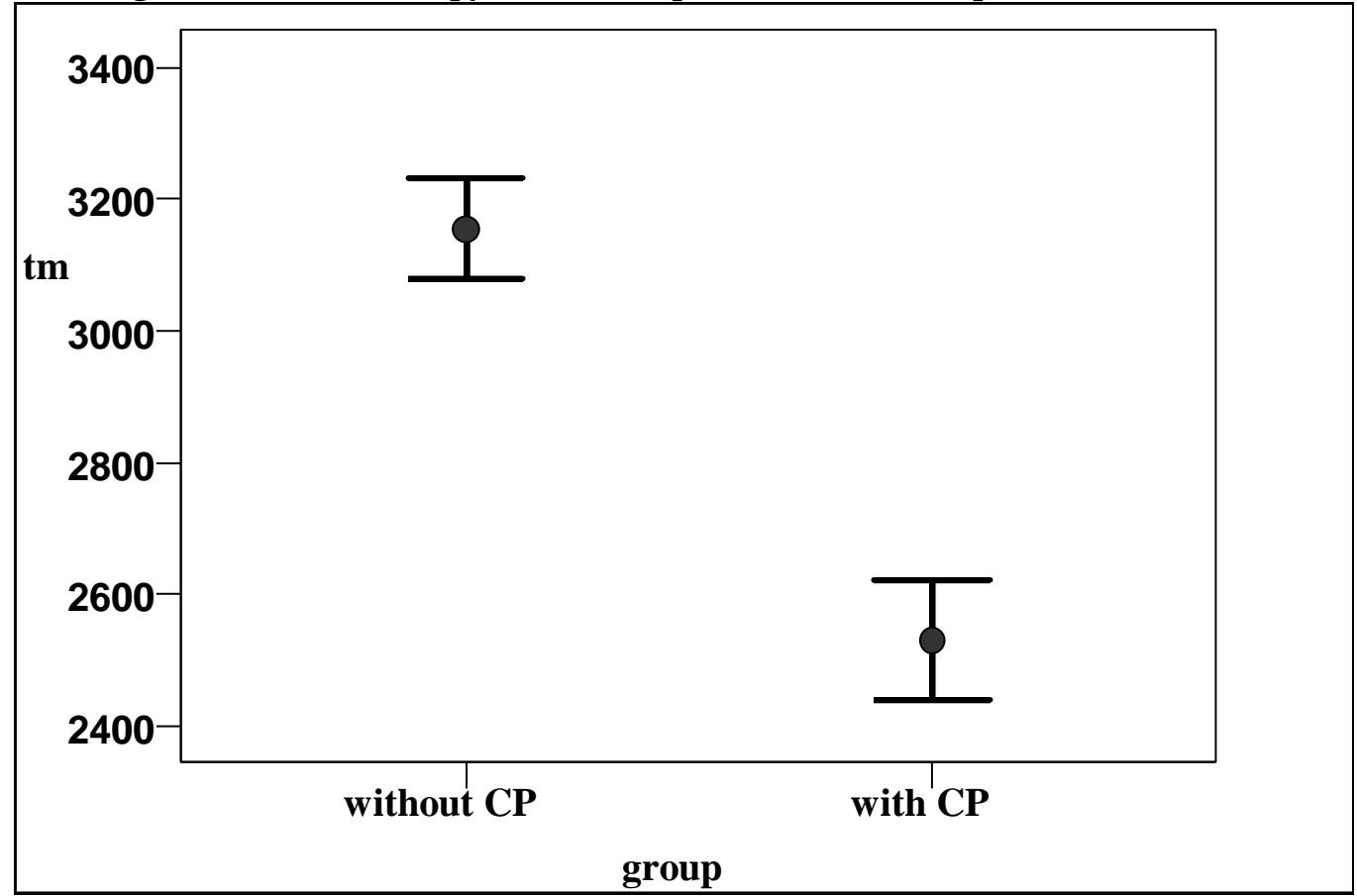

The parameter therapy minutes showed normal distribution (Kolmogorov-Smirnov $\mathrm{p}=0.200$ ). Using the t-test a statistical significance could be calculated $(\mathrm{p}<0.001)$ for the difference between patients without $\mathrm{CP}$ and with CP ( $3154 \pm 455$ vs. $2530 \pm 492$ therapy minutes).

The study shows that a connection exists between the clinical pathway and the therapeutic outlay measured in minutes. An average of 624 therapy minutes could be saved per patient. Age did not play a significant role: although there were significant differences between the two groups, the members of the group with clinical pathway were on average almost six years older than the members of the group without.

\section{DISCUSSION AND CONCLUSION}

The statistical surveys illustrate that the use of the clinical pathway for DRG I42Z (multimode pain therapy in diseases and disturbances of the musculoskeletal system and connective tissue) does not result in a loss of quality. Halving the pain intensity can be interpreted as a quality indicator of inpatient multimode pain therapy.

In order to achieve this therapeutic outcome, the role of the nursing service should be strengthened. This professional group has the closest and most time intensive contact with the patient, is also involved in nursing and pain therapy interventions, and contributes to quality assurance via the standardized documentation 
[26].

Moreover, it is clear that the potential savings are attributable to process optimisations, reduction of informational deficits and optimised interface management. By means of standardized admission management, wrong information about main and secondary diagnosis can already be avoided before involvement of the hospital infrastructure and appropriate procedures can be detailed from the start. The medical and nursing pain anamnesis takes place very soon after allocation to a room, so that in addition to the functional diagnosis, the first pain therapy interventions can be introduced.

Because a hospital exists in an environment characterized by changing circumstances (legal compliance, requirements placed on the quality of organization, processes and outcome, etc.), these tasks and targets cannot be regarded as unique and static. Rather, the permanent modification and adaptation of the business process in the sense of change management is an ongoing responsibility of the hospital management. The success of the management process and core process control can be decisively influenced by efficient process management. It is therefore recommended that clinical pathways be developed for further complex and cost intensive procedures and that the cost and quality efficiency of existing clinical pathways be reviewed.

\section{CONFLICT OF INTEREST} this paper.

The authors have no personal financial or non-financial conflicts of interest related to the publication of

\section{REFERENCES}

[1]. Pain in Europe Study 2003 [cited 2012 Jun 22] Available from: http://www.britishpainsociety.org/Pain\%20in\%20Europ\%20survey\%20report.pdf

[2]. Schonstein E, Kenny DT, Keating J, Koes BW. Work conditioning, work hardening and functional restoration for workers with back and neck pain. Cochrane Database of Systematic Reviews 2003; 1: CD001822.

[3]. Rasmussen C, Nielsen GL, Hansen VK, Jensen OK, Schioettz-Christiensen B. Disc surgery before and after implementation of multidisciplinary nonsurgical spine clinics. Spine 2005; 30: 2469-73.

[4]. Okifuji AA, Turk DC, Kalauokalani D. Clinical outcomes and economic evaluation of the Multidisciplinary Pain Centers. In: Block, A., Kremer, E.E., Fernandez, E., editors. Handbook of Pain Syndromes. Mahwah, NJ: Lawrence Erlbaum Publishers; 1999.p.77-97.

[5]. White AG, Birnbaum HG, Mareva MN, Henckler AE, Grossman P, MallettDA. Economic burden of illness for employees with painful conditions. Journal of Occupational \& Environmental Medicine 2005; 47(9): 884-92.

[6]. Stanley AC, Barry M, Scott T, LaMorte W, Woodson J, Menzoian J. Impact of a critical pathway on postoperative length of stay and outcomes after infrainguinal bypass. Journal of Vascular Surgery 1998; 27: 1056-65.

[7]. Warner BW, Kulick RM, Stoops MM, Metha S, Stephan M, Kotagal UR. An evidence-based clinical pathway for acute appendicitis decreases hospital duration an cost. Journal of Pediatric Surgery 1998; 33: 1371-75.

[8]. Todaro T, Schott-Baer D. Plan faster, healthier recovery after orthopedic surgery. Journal of Nursing Management 2000; 31: 24-26.

[9]. Rotter T, Kugler T, Koch R, Gothe H, Twork S, van Oostrum JM, Steyerberg EW. A systematic review and meta-analysis of the effects of clinical pathways on length of stay, hospital costs and patient outcomes. BMC Health Services Research 2008; 8: 265.

[10]. Gagliese L, Weizblit N, Ellis W, Chan VW. The measurement of postoperative pain: a comparison of intensity scales in younger and older surgical patients. Pain 2005; 117(3): 412-20.

[11]. Ferraz MB, Quaresma MR, Aquino LR, Atra E, Tugwell P, Goldsmith CH. Reliability of pain scales in the assessment of literate and illiterate patients with rheumatoid arthritis. Journal of Rheumatology 1990; 17(8): 1022-4.

[12]. Miller LC, Cox KR. Case management for patients with heart failure: a quality improvement intervention. Journal of Gerontological Nursing 2005; 31: 20-8.

[13]. Gertman PM, Restuccia JD. The appropriateness evaluation protocol: A technique for assessing unnecessary days of hospital care. Med Car1981; 19: 855-871.

[14]. Roeder N, Hensen P. Konsequenzen aus der Einführung eines fallpauschalierten Vergütungssystems.In: Roeder N., Küttner T. Klinische Behandlungspfade. Mit Standards erfolgreicher arbeiten 2007. Dt. Ärzte-Verlag, Köln.

[15]. Stetter F, Kupper S. Autogenic Training: A Meta-Analysis of Clinical Outcome Studies. Applied Psychophysiology and Biofeedback 2002; 27(1): 45-98(54). 
[16]. Townsend CO, Bruce BK, Hooten WM, Rome JD. The Role of Mental Health Professionals in Multidisciplinary Pain Rehabilitation Programs. Journal of Clinical Psychology 2006; 62(11): 14331433.

[17]. Hay EM, Mullis R, Lewis M, Vohora K, Main C, Watson P, Dziedzic KS, Sim J, Minns Lowe C, Croft PR. Comparison of physical treatments versus a brief pain-management programme for back pain in primary care: a randomised clinical trial in physiotherapy practice. The Lancet 2005; 365: 2024-2030.

[18]. Brattberg G. Connective tissue massage in the treatment of fibromyalgia. European Journal of Pain 1999; 3(3): 235-244.

[19]. Molsberger AF. Does acupuncture improve the orthopedic management of chronic low back pain - a randomized, blinded, controlled trial with 3 months follow up.

Pain 2002; 99(3): 579-587(9).

[20]. Meng CF, Wang D, Ngeow J, Lao L, Peterson M, Paget S. Acupuncture for chronic low back pain in older patients: a randomized, controlled trial. Rheumatology (Oxford) 2003; 42,(12): 1508-17.

[21]. Licht S. History of therapeutic heat and cold.In: Lehman J.F.(Ed.), Therapeutic heat and cold. Baltimore, MD, Williams and Wilkins1982; 3: p.1-34.

[22]. Brockow T, Wagner A, Franke A, Offenbächer M, Resch KL. A Randomized Controlled Trial on the Effectiveness of Mild Water-filtered Near Infrared Whole-body Hyperthermia as an Adjunct to a Standard Multimodal Rehabilitation in the Treatment of Fibromyalgia. Clinical Journal of Pain 2007; 23(1): 67-75.

[23]. Cheah J. Clinical pathways--an evaluation of its impact on the quality of care in an acute care general hospital in Singapore. Singapore Medical Journal 2000; 41(7): 335-46.

[24]. Fischer FJ. Clinical Pathways und Evidence based Medicine (EBM) - Perspektiven für die Optimierung von Behandlungspfaden In: Hellmann W.(Ed.), Klinische Pfade 2003, Ecomed.

[25]. Kowal SN, Delaney N. The Economics Of a Nurse-Developed Critical Pathway. Nursing Economic\$ 1996; 14(3).

[26]. Hines PA, Yu KM. The Changing Reimbursement Landscape: Nurses' Role in Quality And Operational Excellence. Nursing Economic\$2009; 27(1).

[27]. 27.DKG (Deutsche Krankenhausgesellschaft 2009) [cited 2012 july 6] Available from: http://www.dkgev.de/dkg.php/cat/62/aid/8061/title/Kostennachweis_der_Krankenhaeuser 